\title{
The process of establishing, implementing and maintaining a social support infant feeding programme
}

\author{
RG Watt ${ }^{1}$ *, P McGlone ${ }^{2}$, JJ Russell ${ }^{1}, \mathrm{KI} \mathrm{Tull}^{1}$ and E Dowler ${ }^{3}$ \\ ${ }^{1}$ Department of Epidemiology and Public Health, University College London, 1-19 Torrington Place, London \\ WCIE 6BT, UK: ${ }^{2}$ University of Plymouth, Plymouth, UK: ${ }^{3}$ University of Warwick, Warwick, UK
}

Submitted 18 July 2005: Accepted 17 November 2005

\begin{abstract}
Objective: To describe the process of establishing and implementing a social support infant feeding intervention.

Design: This paper outlines the initial stages of a randomised controlled trial which assessed the effectiveness of a social support intervention on a range of infant feeding outcomes. Details are presented of the processes involved in recruiting, training and supporting a group of volunteers who provided support to the study sample.

Setting: Camden and Islington, London, UK.

Results: Initial networking with local agencies and organisations provided invaluable information and contacts. Employing a dedicated volunteer co-ordinator is vitally important in the recruitment, training and support of volunteers. Providing child care and travel expenses is an essential incentive for volunteers with young children. Advertisements placed in local newspapers were the most successful means of recruiting volunteers. Appropriate training is needed to equip volunteers with the necessary knowledge and skills to provide effective support. Particular emphasis in the training focused upon developing the necessary interpersonal skills and selfconfidence. The evaluation of the training programme demonstrated that it improved volunteers' knowledge and reported confidence. The provision of ongoing support is also essential to maintain volunteers' interest and enthusiasm. The retention of volunteers is, however, a key challenge.

Conclusions: The processes outlined in this paper have demonstrated the feasibility of successfully establishing, implementing and maintaining a community-based social support infant feeding programme. The experiences described provide useful insights into the practical issues that need to be addressed in setting up a social support intervention.
\end{abstract}

\author{
Keywords \\ Infant Feeding \\ Social support \\ Intervention development
}

Data from national surveys show that contemporary infant feeding practices in the UK are highly variable and in many cases are not in line with current government recommendations ${ }^{1-3}$. For example, the latest Infant Feeding Survey indicates that $70 \%$ of mothers across England and Wales initiate breast-feeding but that rates fall very steeply after a few weeks ${ }^{3}$. Stark inequalities are evident, with many more professional women breastfeeding compared with women living in more disadvantaged circumstances ${ }^{4}$. Other areas of concern include the early introduction of solids and inappropriate foods and drinks being given to infants. For example, a significant number of infants under the age of 4 months are introduced to solids, with cereals and rusks being the most common foods ${ }^{3}$. In contrast, consumption of fruit and vegetables in infancy is low, despite these being ideal first foods.

Infant feeding and weaning practices have both shortand longer-term consequences for the health and development of a child 5 . New mothers want to do their best for their babies but these practices are influenced by a complex array of interrelated factors, many of which are beyond the control of individuals. A considerable amount of research has been undertaken to investigate the effectiveness of different types of interventions to promote breast-feeding. One area which has demonstrated value is the provision of non-professional support to new mothers. Findings from a Cochrane review on support for breastfeeding indicate that social support is effective in promoting exclusive breast-feeding ${ }^{6}$. However, few highquality studies have been undertaken in relation to the promotion of recommended weaning practices in the $\mathrm{UK}^{7}$.

A substantial body of high-quality research has highlighted the positive effects of social support on morbidity and mortality rates ${ }^{8-10}$. Social support is a broad term which encapsulates social relationships and support provided by individuals who are acting in a nonprofessional capacity. Other terms used include 'peer' or 
'lay' support, which all in essence describe contact and support provided by people who share similar sociodemographic characteristics or experiences. Social support affects health by moderating the consequences of stress or through a more direct effect on health and healthrelated behaviours ${ }^{9,10}$. Social networks and support can have a profound impact on individuals' self-esteem, perceptions of self-worth and feelings of powerlessness. Social support can also have more practical value in helping people cope with domestic tasks, sharing information and facilitating access to statutory or voluntary organisations when required ${ }^{8,11}$. Evidence suggests that social support has a more positive effect on health or health-related behaviours, especially in times of stress, if it is provided by individuals of the same sex, age, ethnicity and socio-economic background, or by people who have shared similar life experiences ${ }^{12,13}$.

In relation to maternal and child outcomes, research indicates that social support can have a significant effect $^{14,15}$. A recent Cochrane review of home-based social support for disadvantaged mothers showed that this type of intervention had a positive effect on rates of childhood injury, immunisation levels and number of hospital admissions ${ }^{16}$.

Based upon the encouraging evidence base for social support interventions, a randomised controlled trial (RCT) was commenced in 2002 to evaluate the effect of social support on a range of infant feeding outcomes in a UK sample of lower-income mothers. The study was conducted across the Camden and Islington areas of inner London. The primary aim of the study was to encourage appropriate weaning practices and, in particular, to increase fruit consumption as infants approached their first birthday. A secondary aim was to support mothers who were breast-feeding to continue, in line with current Department of Health guidance. The sample at baseline consisted of 312 mothers whose babies' mean age was 10 (standard deviation 2.16) weeks. Mothers were mainly recruited through baby clinics located in the deprived areas of Camden and Islington. Subjects were randomly allocated to either an intervention or control group. The intervention group received individual, homebased support from trained volunteers from the local community over a 9-month period up until the infant was aged 12 months. Mothers allocated to the control group received standard care and support available from local services.

In the recently published Public Health White Paper, one of the recommendations was the introduction of National Health Service (NHS) health trainers ${ }^{17}$. In this initiative local people will be trained to provide health advice and practical support to people who need assistance in changing and maintaining healthier behaviours. A key element in the success of any social support intervention is securing the active involvement and commitment of the individuals who it is hoped will provide the support to the target group ${ }^{11}$. Understanding the process of setting up and implementing such an intervention is crucially important. Insights into the process of recruiting, training and supporting volunteers are needed if the intervention is to achieve its goals and be sustained in the longer term ${ }^{18}$. However, very few papers describe the steps involved in setting up a social support intervention. The aim of the present paper is therefore to describe the process of establishing and implementing a social support infant feeding intervention. It is hoped that the experiences gained in the early stages of setting up this RCT will be of value to others planning to establish any form of social support intervention. A description is given of the steps involved in establishing the intervention.

\section{Engaging with local partners}

In the first few months of the project a considerable amount of time was spent meeting with the wide range of relevant local agencies and organisations involved with child health and well-being (Fig. 1).

Engagement and communication with representatives from local statutory and voluntary organisations was an immensely worthwhile activity, particularly those who regularly recruit and work with local volunteers. As well as raising the profile of the project with key local stakeholders, the meetings also provided very valuable information on a whole range of practical and organisational issues specifically in relation to the recruitment and training of volunteers. For example, one very important piece of advice in the British context related to the procedural difficulties of being able to pay volunteers for their time on a project. Once payment is provided, contracts of employment are often required and volunteers need to declare any earnings which may impact upon any welfare benefits entitlement.

Prior to the recruitment and training of volunteers careful planning was required to organise practical details such as locating and booking suitable venues for interviewing and training potential volunteers. In

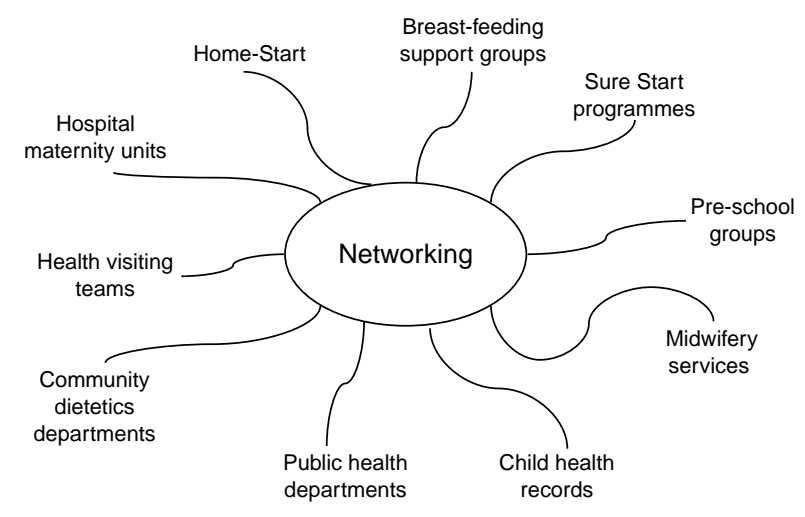

Fig. 1 Organisations contacted 
a community-based project, care is required in selecting a comfortable and non-threatening venue for training. University or NHS premises may be very intimidating places for many people who do not have formal qualifications or who have had negative experiences of the education or health system. However, community venues are very busy places much in demand, and are therefore often difficult to book and may be crowded and noisy. Ideally venues need to be accessible, have crèche facilities on site and be able to provide suitable refreshments.

\section{Recruitment of volunteers}

It was estimated that between 35 and 40 volunteers would need to be recruited and trained. This estimate was based upon the fact that approximately 160 mothers would receive volunteer support, and that each volunteer would be allocated an average of four or five mothers. Evidence from the social support literature indicates that better outcomes are achieved when the peers and individuals they are supporting are similar in terms of socio-economic background ${ }^{12,13}$. Therefore every effort was made to recruit volunteers who would be as similar in background and circumstances to the mothers who were the intended focus of the study. Volunteers were required to be mothers, living locally within the Camden or Islington areas or neighbouring boroughs, be able to speak and write in English and commit to the project for a minimum of 9 months. The language requirement was due to the fact that volunteers were required to complete a variety of monitoring forms as part of the wider research study.

To limit the size of the training groups, four waves of recruitment were undertaken over a 12-month period between October 2002 and September 2003. A variety of recruitment techniques was employed over this period (Table 1).

Initially, several hundred fliers were posted out to a range of local organisations and venues where potential volunteers might be found. Very little interest was stimulated by this mailing, however. Our experience was that the most successful method of attracting interest in the project was through placing advertisements in local newspapers. Of the 54 individuals subsequently interviewed to be volunteers, this method attracted 49 women.

Table 1 Volunteer recruitment methods

Fliers distributed to Early Years centres, nursery schools,
community centres, local libraries and play groups
Direct approaches to mothers in street
Notice placed in volunteer bureau
Advertisements in local papers (free and paid)
Mail out to Sure Start members

When an individual contacted the study team expressing interest in the project, a date for an informal interview was agreed as quickly as possible to maintain their initial interest. The interview was carried out by two members of the project team in an informal style. The interviews lasted approximately 20 minutes and focused upon the individual's motivation for applying to become a volunteer, their experience of being a parent, any previous relevant work or volunteering experience, and their insight into the problems new mothers may face feeding their child. During the discussion, evidence of an understanding and empathetic approach was assessed. In addition to the interview, applicants were asked to complete a basic application form for their contact details, the name and address of two character referees, contact details for their general practitioner to enable medical clearance, and information on any previous work or volunteering experience. A completed declaration regarding criminal convictions was also requested and applicants were notified that a Criminal Records Bureau check would be undertaken at an enhanced level. Completion of the application form also provided information on the applicants' literacy and level of written English. Also at the interview the applicants were provided with details about the nature of the project, training programme and the practical arrangements for paying travel and childcare costs at a maximum rate of $\$ 5.00$ per hour. The decision to accept or reject an applicant was made by both interviewers. In total 54 individuals were interviewed, of whom 46 were accepted, 43 commenced and 39 completed the initial training programme. The main reason for rejecting applicants was their inability to commit to the project for the timescale required.

The main motivations given by those wishing to become a volunteer in the project were:

- Interest in helping other new mothers.

- Wish to meet other individuals.

- Interest in nutrition.

- Desire for training and experience to facilitate future employment and further education.

In other words, in common with general findings on volunteer motivations, a range of reasons was given why they had applied for this project ${ }^{19}$.

\section{Volunteer training}

Initially, staff from the local Home-Start team provided valuable practical assistance and expertise in developing the training programme and working with volunteers. Training a diverse group of individuals to be effective volunteers requires a good deal of careful planning and preparation. Although the primary focus of the project was to promote recommended infant feeding practices, 
a range of related topics and practical issues had to be covered in the training sessions.

\section{Overview of training programme}

Effective training should be tailored to the needs and experience of the participants ${ }^{20}$. The programme adopted an informal, empowering and interactive style of training which encouraged the participants to engage practically with the topics covered and to interact with each other. Role play and other activities were used to develop the participants' interpersonal skills. The importance of adopting a non-judgemental approach was stressed throughout the training. Participants were encouraged to reflect upon their own experiences of infant feeding and to consider ways in which mothers could be supported.

The aim of the training programme was to equip volunteers with the relevant knowledge, attitudes and skills to provide appropriate support and advice to new mothers regarding infant feeding practices. Four waves of training took place between November 2002 and October 2003 with groups of eight to 16 participants. Each training programme was run over a 3-week period with four or five sessions timetabled per week (Table 2). Sessions commenced at 10 am and finished at $2.30 \mathrm{pm}$, with an hour allocated for breaks and lunch. Each programme therefore consisted of approximately 54 hours' training in total. As well as focusing on infant nutrition, important topics such as child protection, equal opportunities, confidentiality and personal safety were also covered. A team of experienced trainers from a range of organisations and backgrounds delivered the sessions. As a means of evaluating the training, pre and post quizzes were used to assess changes in both nutritional knowledge and general confidence. In addition, a mid-programme quiz was used to determine how well the participants were progressing with the

Table 2 Training programme summary

\begin{tabular}{|c|c|}
\hline Day & Session title \\
\hline Day 1 & $\begin{array}{l}\text { Introductions } \\
\text { Project overview }\end{array}$ \\
\hline Day 2 & $\begin{array}{l}\text { Influences on eating } \\
\text { Breast-feeding - benefits and barriers }\end{array}$ \\
\hline Day 3 & Equal opportunities \\
\hline Day 4 & $\begin{array}{l}\text { Supporting mothers who breast-feed } \\
\text { Infant feeding up to } 6 \text { months }\end{array}$ \\
\hline Day 5 & $\begin{array}{l}\text { Confidentiality and commitment } \\
\text { Family and child needs }\end{array}$ \\
\hline Day 6 & Infant feeding 6-9 months \\
\hline Day 7 & $\begin{array}{l}\text { Support services } \\
\text { Record keeping }\end{array}$ \\
\hline Day 8 & $\begin{array}{l}\text { Boundaries } \\
\text { Listening skills }\end{array}$ \\
\hline Day 9 & $\begin{array}{l}\text { Infant feeding 9-12 months } \\
\text { Personal safety and endings }\end{array}$ \\
\hline Day 10 & Feeding a toddler \\
\hline Day 11 & Child protection \\
\hline Day 12 & Food hygiene \\
\hline Day 13 & $\begin{array}{l}\text { Review and recap } \\
\text { Evaluation }\end{array}$ \\
\hline
\end{tabular}

training. At the end of each session participants also completed an evaluation form to provide feedback. Details of the evaluation are outlined below.

\section{Training materials and supporting resources}

To fulfil the requirements of research governance and to meet the training needs of the volunteers, a wide range of materials and policies and guidelines were utilised (Table 3). Existing materials used in other volunteer training programmes were adapted where possible. Copies of all these documents are available on request and may be modified for use in local projects.

\section{Evaluation of training programme}

Evaluation of any training programme is a core element of good practice ${ }^{19}$. In projects working with volunteers it is especially important that an appropriate and nonthreatening assessment is made of the knowledge and confidence required to perform their support role adequately. It is essential to ensure consistency in the information volunteers will be providing to those they will be supporting. All the volunteers in this project were therefore asked to complete a quiz at the beginning and the end of the training programme. The quiz contained a number of questions assessing knowledge of infant feeding guidelines. In addition, a series of questions also assessed the volunteers' level of reported confidence in being a volunteer. A total of 39 volunteers completed the baseline and end-of-training evaluation.

A total score of 51 could be achieved in the knowledge assessment. The scores were calculated on the basis of a score of 1 for a correct answer. None of the questions was weighted. The range at baseline was $22-47$ and at the end of training was 29-51. The mean score was 37 at baseline and 44 at the end of the training; the median scores were 39 and 46, respectively (Fig. 2). This was a highly significant gain in knowledge $(P<0.0005$, paired $t$-test). The mean change in the score was an increase of 7 points from baseline to the end of the training. Those with the lowest scores achieved the greatest amount of change.

Table 3 Training materials and resources

Volunteer/University College London agreement

Volunteer information sheet

Volunteer consent form

Personal safety guidelines

Medical reference form

Disclosure application form

Confidentiality policy

Course handouts

Evaluation forms

Volunteer profile forms

Self-reflection evaluation forms

Resource handbook

Recipe book 


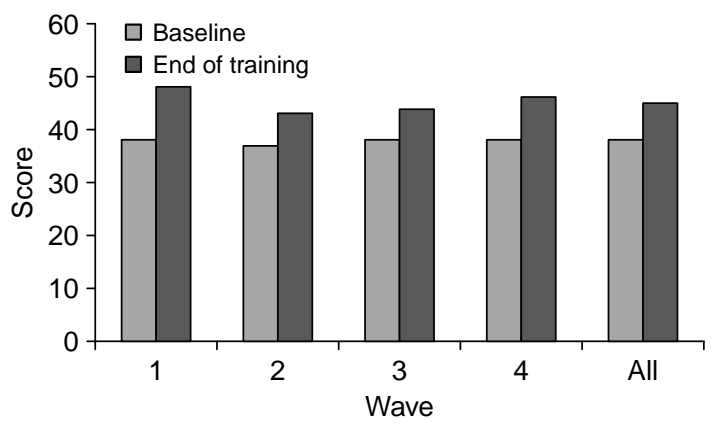

Fig. 2 Scores for quiz at baseline and end of training

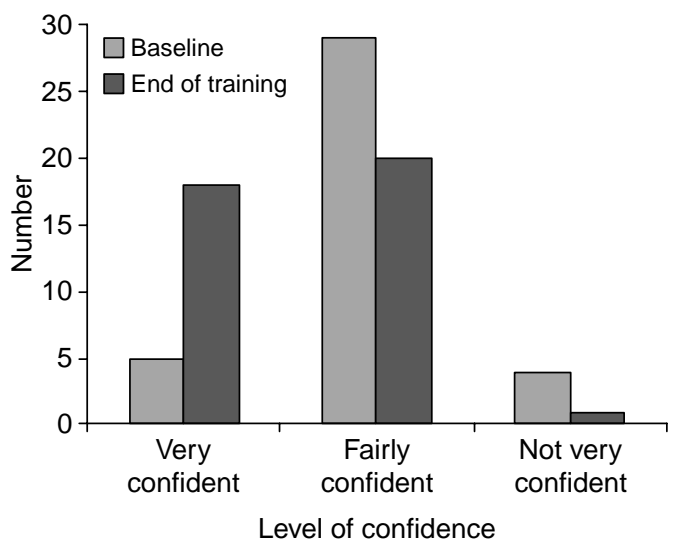

Fig. 3 Confidence in knowledge of guidelines on infant feeding

Figure 3 shows the perceived level of confidence in knowledge of infant feeding guidelines. Only five volunteers reported being very confident at the beginning of the training, compared with 18 at the end of the training.

At baseline most of the volunteers reported that they were either very confident $(n=15)$ or fairly confident $(n=24)$ that they would be able to act as volunteers for the project. A significant change in reported confidence was noted, with 18 volunteers being very confident at the end of the training and 20 reporting to be fairly confident. Finally, at baseline 22 volunteers reported that they were very confident, and 16 fairly confident, in their ability to commit to being involved in the study for 9 months; this changed to 25 and 14, respectively, at the end of training.

\section{Supporting volunteers}

In the initial development and planning stages of the project, the importance of supporting the trained volunteers in their activities and the resources required to do this properly were greatly underestimated. After the first training programme was completed it became apparent that a dedicated member of staff was needed to support the volunteers in their work. Fortunately, the project funding agency provided additional resources to employ a volunteer coordinator (3 days per week) for an 18-month period.

\section{Role of volunteer co-ordinator}

A key element in running a social support project is the appointment of an experienced and skilled volunteer co-ordinator. The co-ordinator needs to perform a range of important tasks in recruiting, training, matching and supporting the volunteers. Excellent interpersonal and organisational skills are essential to perform these tasks well. Dealing emphatically with volunteer queries takes a considerable amount of time and skill. In addition, maintaining the enthusiasm and commitment of volunteers is very important in ensuring that support programmes are sustained. Adopting an understanding and flexible approach with volunteers is essential.

\section{Matching process}

On completion of the first wave of training it became apparent that once the volunteers had completed their initial training it was important they were matched up with the individual they were to support as soon as possible, to maintain their interest in the project. Matching volunteers with mothers required careful consideration of the needs and circumstances of both parties. To assure confidentiality and maintain appropriate boundaries, volunteers were not matched with any mothers who lived in their immediate vicinity or who they knew directly or through mutual friends.

It was recognised that the first visit between the volunteer and the mother they were to support could be a difficult and stressful time for both individuals. To address this problem, the volunteer co-ordinator arranged to accompany volunteers on their first visits. This helped to boost the volunteer's confidence and enabled the mother to ask any questions about the project.

\section{Monitoring and payment systems}

As a means of monitoring volunteer visits and to give some indication of the quality of the support provided, after each visit volunteers were required to complete and return forms detailing the nature of their visit. This system also helped the volunteer co-ordinator to answer any questions that may have arisen in the course of the visits. In addition, the monitoring forms enabled an assessment to be made that any information given was in line with current guidelines. To maintain confidentiality no names or other identifying information were included in the monitoring forms.

To ensure that volunteers were reimbursed promptly for their travel and childcare costs, an efficient expenses request payment system was established. Whenever possible, expenses were paid into volunteers' bank accounts within 1 week of the visit. This was considered particularly important when working with volunteers from lower-income households. 


\section{Support meetings}

It rapidly became clear that ongoing support was very important to maintain volunteers' enthusiasm and ability to provide support. Every eight weeks a support meeting was held between the hours of 10 am and 2 pm. These meetings were generally well attended, and provided an opportunity for further training and, most importantly, the development of group support, mutual encouragement and a shared goal. For part of each session, an outside speaker would address the group on a relevant topic. The remainder of the time was spent discussing issues amongst the group and sharing their experiences of the project. Skilful facilitation was needed to develop the volunteers' confidence and sense of purpose. Topics covered in these support meetings are outlined in Table 4. Thus volunteers received opportunities for the development of relevant knowledge and skills.

\section{Recognition of volunteers' work}

As the project progressed it was increasingly apparent that a proportion of the volunteers was unable to continue due to changing personal and family circumstances. Of the 39 volunteers who completed the initial training programmes, 25 were still actively involved at the end of the intervention phase. Ongoing recruitment and training of new volunteers was therefore essential to maintain a critical mass of committed volunteers.

As a way of thanking the volunteers for their work, a celebration event was organised at the end of the intervention phase of the project. Davina McCall, a wellknown television presenter, was invited to hand out 'portfolios of achievement' to each volunteer. The portfolio consisted of a personal reference, details of the project and training programme, and a personal certificate. The event stimulated considerable local press coverage, and was a very enjoyable ending to the project for the volunteers.

It was originally intended that external accreditation for the training programme would be sought to aide the volunteers in seeking future employment or further education. After many attempts, accreditation was not secured mainly due to the complex bureaucratic procedures required.

\section{Table 4 Topics covered in support meetings}

Breast-feeding support
Foundation Certificate in Food Hygiene
Eating problems in young children
Nutritional update on fruit and vegetables
Role of health visitors
Sure Start services
Oral health and drinks
Food labelling
Recipe ideas
Local support services

\section{Discussion}

Formative evaluation is an important stage in the evaluation process in health promotion planning ${ }^{21}$. However, few papers report on the experiences and insights gained in the early stages of developing and implementing an intervention. In this study we have demonstrated the feasibility of developing a social support programme to promote recommended weaning and infant feeding practices. Future papers will outline details of the process and outcome evaluation of the intervention. Over a two-year period a substantial number of volunteers have been recruited and trained to provide support to a significant number of new mothers living in a deprived inner-city location. What are the key lessons learned from this experience which may have wider relevance? In England, NHS health trainers will soon be trained to provide health advice and support to members of their local community ${ }^{17}$. What is the best way of recruiting and training these volunteers? What support will be required to enable volunteers to perform their role effectively?

To successfully establish a social support programme requires careful initial planning and engagement with existing local agencies and services. These initial stages take a considerable amount of time and effort which must be planned into the schedule, but provide invaluable information and greatly assist the subsequent implementation process. The recent evaluation of breast-feeding peer support programmes highlighted the importance of building on existing infrastructure and the need for comprehensive planning ${ }^{22}$. Reports of other social support nutrition interventions have highlighted the difficulties in recruiting appropriate volunteers ${ }^{18}$. In the present project a large and diverse group of volunteers was successfully recruited, largely through the placement of advertisements in local newspapers. The provision of expenses to cover travel and childcare costs greatly helped the recruitment of women from a range of backgrounds. It also acknowledges the contribution volunteering women make and affords them respect. Failure to provide appropriate expenses may have restricted the volunteers to largely middle-class women and this would have adversely affected the ability of the project to support mothers with the greatest needs from more disadvantaged households.

The effectiveness of volunteers in the three areas of knowledge, delivery and sensitivity has been shown to be important in the success of social support interventions ${ }^{23}$. It is essential therefore that appropriate training is offered to develop volunteers' knowledge and skills required to provide effective support. Rather than placing too much emphasis on acquiring factual knowledge, practical skills training is needed to develop the interpersonal and communication skills required to provide non-judgemental encouragement. The contents of training need to emphasise the unique role played by volunteers and the 
way in which their activity complements the services provided by professionals. Training that concentrates too heavily on the clinical aspects may have the effect of distancing the volunteers from the individuals they support ${ }^{24}$. In this project the training programme focused very much on developing practical communication skills to deliver emphatic support and encouragement. This was achieved through the use of role play and participative training exercises. The evaluation of the training demonstrated significant changes in both the necessary knowledge and confidence to provide support to new mothers on infant feeding practices. However, no information was collected on the impact of the project on the volunteers' social networks. McInnes and Stone have described the process of implementing a peer breast-feeding support programme and highlighted the need to assess the impact on volunteers' social networks ${ }^{25}$.

A core principle of health promotion is the need to empower individuals and communities to increase their control over the determinants of health ${ }^{26-28}$. Effective adult training needs to empower the participants through building up their self-confidence and self-esteem ${ }^{29}$. In this project interactive training methods were used to encourage the volunteers to share their own experiences and the ways in which they coped with the pressures and problems of feeding a baby. Guidelines and policies were developed to provide clarity and focus for the volunteers. These have been shown to help volunteers be clear on their precise role in a project and the responsibilities of their supervisors ${ }^{17}$. Finally, to maintain a social support intervention, it is essential that volunteers are provided with ongoing support and encouragement ${ }^{22,24}$. Without this, retention of volunteers becomes a major challenge ${ }^{18,22}$. In this project a dedicated volunteer coordinator was appointed to perform this task. The appointment of an experienced and appropriately trained individual is essential. A monitoring system was established which provided a useful means of checking volunteers' activities and providing any necessary advice. Regular support meetings were organised for the volunteers and this provided a valuable opportunity for sharing experiences and problems encountered and the provision of training updates. The meetings also helped a group identity to be developed which undoubtedly increased the volunteers' commitment and enthusiasm for the project. Sustainability is a major challenge for many community food projects ${ }^{19}$. In this study a high proportion of volunteers were retained throughout the programme. The ongoing support provided undoubtedly helped to retain an active and enthusiastic group of volunteers.

Conflict may arise between health professionals and volunteers when respective roles are not fully understood and appreciated ${ }^{22}$. In this project, communication with local health visiting teams and other professional groups was maintained through the production of newsletters and holding regular meetings with key decision-makers. This helped to avoid any confusion or conflict arising, and also facilitated securing ongoing funding in one of the Primary Care Trusts to continue the programme in the longer term.

What problems emerged during this stage of the project? One was that, from a public health perspective, with certain minority ethnic groups infant feeding practices are a particular problem ${ }^{2}$. In this study due to funding restrictions and for logistical reasons it was not possible to include subjects who were not able to communicate effectively in English. Although the volunteers recruited came from a diverse range of ethnic groups, the support provided was always in English. Specially tailored social support interventions may be needed for different ethnic minority populations where English is not their first or second language. Another problem was that although every effort was made to recruit and retain volunteers who were young mothers, this proved very difficult to implement. The average age of the volunteers was 36 years, and the majority of the younger volunteers recruited either did not complete the training or dropped out in the early stages of the project. Recruiting and maintaining the interest of young volunteers in a project focusing on infant feeding is a significant challenge. Many younger people do not perceive that they have a role in one-to-one caring voluntary work and instead consider this to be more the domain of middle-aged women ${ }^{30}$. Further research is required to assess ways of encouraging participation of younger people in this type of voluntary work. Finally, the external accreditation of training in volunteer programmes provides a useful incentive for participants as it facilitates access to further training or employment opportunities ${ }^{17}$. Although every effort was made to secure accreditation of the training programme developed in this project, this was not achieved. Several different options such the National Vocational Qualification or Open College Network provide accreditation but the process of securing course recognition is complex, time-consuming and costly.

In conclusion, this paper has outlined the steps involved in successfully establishing, implementing and maintaining a community-based social support infant feeding programme. The experiences described provide useful insights into the practical issues that need to be addressed.

\section{Acknowledgements}

This project was funded by the Food Standards Agency. The authors would like to thank all the volunteers who participated in this study for their hard work, dedication and good will. Thanks are also due to the following individuals for their advice and support: Jackie Blasi, Brenda Molloy, Sam Sargent, Louise Hodge and Meg Wiggins. 


\section{References}

1 Foster K, Lader D, Cheesbrough S. Infant Feeding 1995. London: The Stationery Office, 1997.

2 Thomas M, Avery V. Office for National Statistics. Infant Feeding in Asian Families. London: The Stationery Office, 1997.

3 Hamlyn B, Brooker S, Oleinikova K, Wands S. Infant Feeding 2000. London: The Stationery Office, 2002.

4 Kelly Y, Watt R. Breast-feeding initiation and exclusive duration at 6 months by social class - results from the Millennium Cohort Study. Public Health Nutrition 2005; 8: 417-21.

5 Darnton-Hill I, Nishida C, James WPT. A life course approach to diet, nutrition and the prevention of chronic diseases. Public Health Nutrition 2004; 7: 101-21.

6 Sikorski J, Renfrew MJ, Pindoria S, Wade A. Support for breastfeeding mothers. Cochrane Database of Systematic Reviews 2002; (1): CD001141.

7 Tedstone A, Dunce N, Aviles M, Shetty P, Daniels L. Effectiveness of Interventions to Promote Healthy Feeding in Infants under One Year of Age: A Review. London: Health Education Authority, 1998.

8 Cohen S, Syme L. Social Support and Health. New York: Academic Press, 1985.

9 Cooper H, Arber S, Fee L, Ginn J. The Influence of Social Support and Social Capital on Health. A Review and Analysis of British Data. London: Health Education Authority, 1999.

10 Stansfeld S. Social support and social cohesion. In: Marmot M, Wilkinson RG, eds. Social Determinants of Health. Oxford: Oxford University Press, 1999; 155-78.

11 Dean K, Hancock T. Supportive Environments for Health. Copenhagen: World Health Organization, 1992.

12 House J. Work, Stress and Social Support. Reading, MA: Addison-Wesley, 1981.

13 Cohen S, McKay G. Social support, stress and the buffering hypothesis, a theoretical analysis. In: Baum A, Singer J, Taylor S, eds. Handbook of Psychology and Health. Hillsdale, NJ: Laurence Erlbaum, 1984; 253-67.

14 Oakley A. Is social support good for the health of mothers and babies? Journal of Reproduction and Infant Psychology 1988; 6: 3-21.

15 Johnson Z, Howell F, Molloy B. Community mothers programme: randomised controlled trial of a non-professional intervention in parenting. British Medical Journal 1993; 306 : $1449-52$.

16 Hodnett E, Roberts I. Home-based social support for socially disadvantaged mothers. Cochrane Database of Systematic Reviews 2000; (2): CD000107.

17 Department of Health. Choosing Health - Making Healthy Choices Easier. London: Department of Health, 2004.

18 Taylor T, Serrano E, Anderson J. Management issues related to effectively implementing a nutrition education program using peer educators. Journal of Nutrition Education 2001; 33: $284-9$.

19 McGlone P, Dobson B, Dowler E, Nelson M. Food Projects and How They Work. York: Joseph Rowntree Foundation, 1999.

20 Ewles L, Simmnett I. Promoting Health. A Practical Guide. London: Bailliere Tindall, 1999.

21 Ovretveit J. Evaluating Health Interventions. Buckingham: Open University Press, 1998.

22 Dykes F. Government funded breastfeeding peer support projects: implications for practice. Maternal and Child Nutrition 2005; 1: 21-31.

23 Croll N, Jurs E, Kennedy S. Total quality assurance and peer education. Journal of the American College of Health 1993; 41: $247-51$

24 Meister J, Warrick L, deZapien J, Wood A. Using lay health workers: case study of a community-based prenatal intervention. Journal of Community Health 1992; 17: 37-51.

25 McInnes R, Stone D. The process of implementing a community-based peer breastfeeding support programme: the Glasgow experience. Midwifery 2001; 17: 65-73.

26 World Health Organization (WHO). The Ottawa Charter for Health Promotion. Health Promotion 1. Geneva: WHO, 1986; i-v.

27 Beattie A. Knowledge and control in health promotion: a test case for social policy and social theory. In: Gabe J, Calna M, Bury M, eds. The Sociology of the Health Service. London: Routledge, 1991.

28 Tones K, Tilford S, eds. Health Education: Effectiveness, Efficiency and Equity. London: Chapman and Hall, 1994.

29 Freire P. Pedagogy of the Oppressed. New York: Herder and Herder, 1970.

30 Walker C, Fisher A. Growing into Giving: Young People's Engagement with Charity. Kent: Charities Aid Foundation, 2002. 